\title{
Quantitative proteomic analysis reveals the ethanologenic metabolism regulation of Ethanoligenens harbinense by exogenous ethanol addition
}

\author{
Huahua Li, Xiaoxue Mei, Bingfeng Liu, Guojun Xie, Nanqi Ren and Defeng Xing ${ }^{*}$ (D)
}

\begin{abstract}
Background: $\mathrm{H}_{2}$-ethanol-coproducing bacteria, as primary fermenters, play important roles in the microbiome of bioreactors for bioenergy production from organic wastewater or solid wastes. Ethanoligenens harbinense YUAN-3 is an anaerobic ethanol- $\mathrm{H}_{2}$-fermenting bacterium. Ethanol is one of the main end-products of strain YUAN-3 that influence its fermentative process. Until recently, the molecular mechanism of metabolic regulation in strain YUAN-3 during ethanol accumulation has still been unclear. This study aims to elucidate the metabolic regulation mechanisms in strain YUAN-3, which contributes to effectively shape the microbiome for biofuel and bioenergy production from waste stream.

Results: This study reports that ethanol stress altered the distribution of end-product yields in the $\mathrm{H}_{2}$-ethanolcoproducing Ethanoligenens harbinense strain YUAN-3. Decreasing trends of hydrogen yield from $1888.6 \pm 45.8$ to $837 \pm 64.7 \mathrm{~mL} \mathrm{~L}^{-1}$ and acetic acid yield from $1767.7 \pm 45$ to $160.6 \pm 44.7 \mathrm{mg} \mathrm{L}^{-1}$ were observed in strain YUAN-3 with increasing exogenous ethanol (0 mM-200 mM). However, the ethanol yield of strain YUAN-3 increased by 15.1\%, $30.1 \%$, and $27.4 \%$ in $50 \mathrm{mM}, 100 \mathrm{mM}$, and $200 \mathrm{mM}$ ethanol stress, respectively. The endogenous ethanol accounted for $96.1 \%(\mathrm{w} / \mathrm{w}$ ) in liquid end-products when exogenous ethanol of $200 \mathrm{mM}$ was added. The molar ratio of ethanol to acetic acid increased 14 times (exogenous ethanol of $200 \mathrm{mM}$ ) compared to the control. iTRAQ-based quantitative proteomic analysis indicated that 263 proteins of strain YUAN-3 were differentially expressed in $50 \mathrm{mM}, 100 \mathrm{mM}$, and $200 \mathrm{mM}$ of exogenous ethanol. These proteins are mainly involved in amino acid transport and metabolism, central carbon metabolism, and oxidative stress response.
\end{abstract}

Conclusion: These differentially expressed proteins play important roles in metabolic changes necessary for growth and survival of strain YUAN-3 during ethanol stress. The up-regulation of bifunctional acetaldehyde-CoA/alcohol dehydrogenase (ADHE) was the main reason why ethanol production was enhanced, while hydrogen gas and acetic

\footnotetext{
*Correspondence: dxing@hit.edu.cn

State Key Laboratory of Urban Water Resources and Environment, School

of Environment, Harbin Institute of Technology, P.O. Box 2614, No. 73

Huanghe Road, Nangang District, Harbin 150090, Heilongjiang, China
}

(c) The Author(s) 2019. This article is distributed under the terms of the Creative Commons Attribution 4.0 International License (http://creativecommons.org/licenses/by/4.0/), which permits unrestricted use, distribution, and reproduction in any medium, provided you give appropriate credit to the original author(s) and the source, provide a link to the Creative Commons license, and indicate if changes were made. The Creative Commons Public Domain Dedication waiver (http://creativecommons.org/ publicdomain/zero/1.0/) applies to the data made available in this article, unless otherwise stated. 
acid yields declined in strain YUAN-3 during ethanol stress. This study also provides a new approach for the enhance-
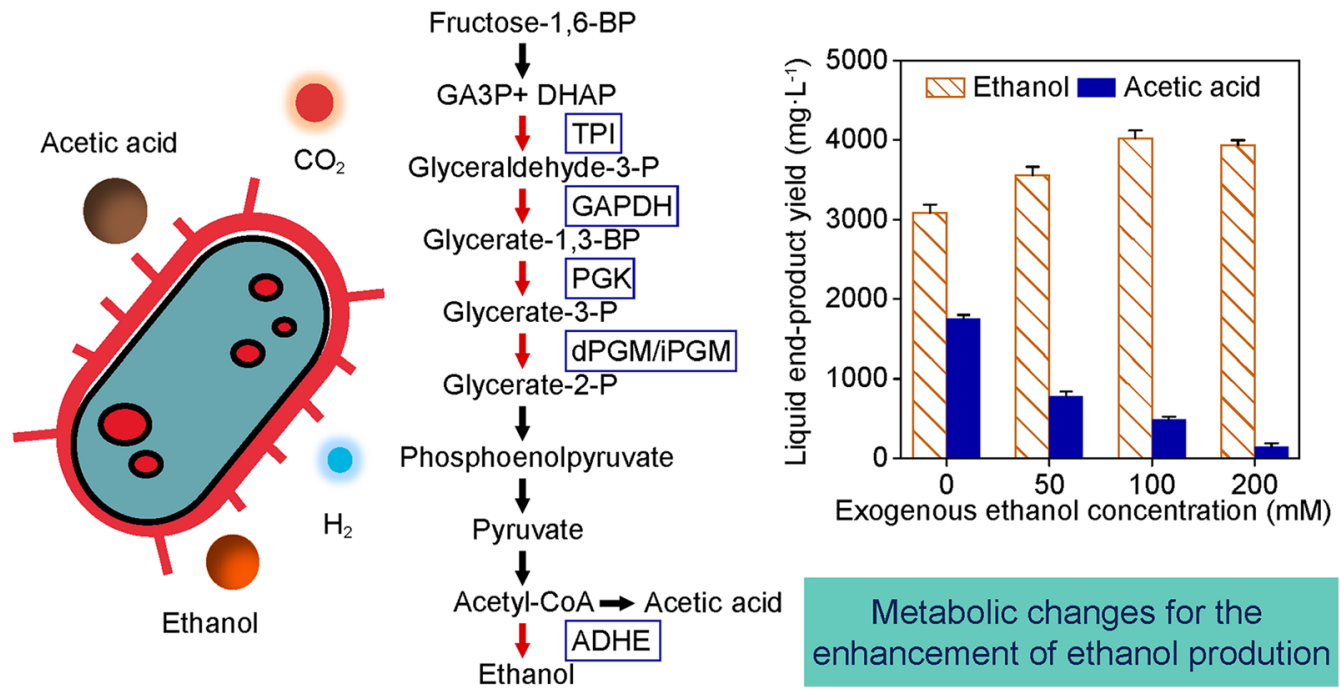

ment of ethanologenesis by $\mathrm{H}_{2}$-ethanol-coproducing bacteria through exogenous ethanol addition.

Keywords: Hydrogen-producing bacteria, Ethanologenesis, Ethanoligenens harbinense, Ethanol stress, Quantitative proteomics

\section{Background}

Microorganisms play crucial roles in biological wastewater treatment process which can effectively remove organic matters and simultaneously achieve energy recovery [1-3]. Hydrogen-producing species in activated sludge and biofilms are responsible for providing electron to methanogenesis, homoacetogenesis, and other terminal electron-accepting processes such as sulfate reduction and denitrification [4]. Gaseous hydrogen is an efficient electron carrier; recent studies revealed that hydrogen is widely used as an energy source for microbial growth and survival in biological systems. Microbial hydrogen metabolism was more widely spread than previously reported [5-7]. Ethanoligenens harbinense is an anaerobic ethanol- $\mathrm{H}_{2}$-fermenting bacterium, and the type strain YUAN-3 forms autoaggregating granules which is benefit to the formation of anaerobic granular sludge and maintenance of high cell density in continuous-flow bioreactors [8-10]. The end-products are composed of ethanol, acetic acid, $\mathrm{H}_{2}$, and $\mathrm{CO}_{2}$ [11], which can also be subsequently used by other microbial species through cross-feeding interactions in anaerobic digestion and bioelectrochemical systems (BES) to achieve higher energy recovery from organic wastes [12-14]. $\mathrm{H}_{2}$ and ethanol can be used directly as bioenergy and biofuel. Moreover, ethanol and acetic acid can also be converted into mediumchain fatty acids (MCFAs) by naturally present bacteria through reverse $\beta$-oxidation reaction. Additionally,
MCFAs are easier to extract from water and are more versatile than ethanol and acetic acid $[15,16]$.

Metabolic flexibility contributes to the survival and fitness of microbial species in a changing environment [17, 18]. Decreasing pH value enhanced ethanol productivity and reduced acetic acid accumulation in Clostridium autoethanogenum [19]. Eight percent oxygen exposure resulted in higher ethanol yield and lower acetate yield in Clostridium ljungdahlii [20]. A decrease in $\mathrm{pH}$ is also the main factor that induces metabolic change from organic acids production to solvents production in acetone-butanol-ethanol (ABE)-fermenting bacteria [21]. Increased 3-methylbutanoic and 2-methylbutanoic acid production and reduced primary carbohydrate metabolite production were observed in Lactobacillus sanfranciscensis LSCE1, which is considered to be induced by acid stress [22]. Ethanol is one of the liquid end-products of strain YUAN-3 that influence its fermentative process [8]. However, the molecular mechanism of metabolic regulation in Ethanoligenens harbinense strain YUAN-3 during ethanol accumulation is still unclear.

End-product accumulation frequently causes inhibitory effects on cell physiology [23]. Microbial ethanol stress response has generally been described to be a complex biological process [24-26]. Ethanol stress increased 

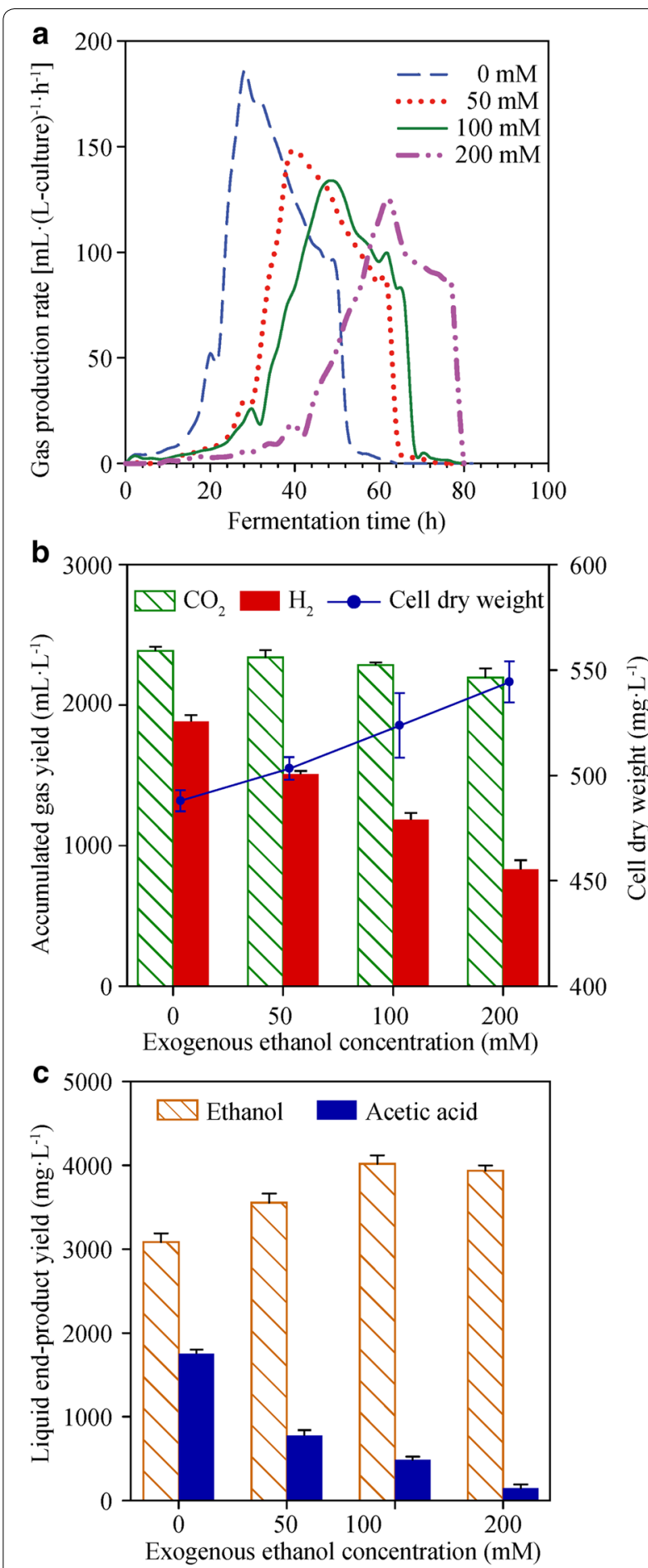

Fig. 1 Effect of ethanol stress on end-products and cell dry weight of strain YUAN-3. a Gas production rate and fermentation time, $\mathbf{b} \mathrm{H}_{2}$ $\mathrm{CO}_{2}$ yield, and cell dry weight, $\mathbf{c}$ ethanol and acetic acid yields membrane fluidity and denatured proteins within the cytosol and membrane, which adversely affected metabolism thus decreasing the cell growth of bacteria [27]. A previous study has proposed that translation and transcription are important processes negatively affected by ethanol. Ethanol caused the inhibition and uncoupling of mRNA and protein synthesis by directly influencing ribosome and RNA polymerase conformations in E. coli [28]. More recently, the effect of ethanol on the global metabolic response in Oenococcus oeni was carried out using an extended genome-scale metabolic model. The results indicated that the requirements of $\mathrm{NAD}(\mathrm{P})^{+}$and $\mathrm{ATP}$ increased in ethanol stress, and the strain required 10 and 17 times more ATP for non-growth associated maintenance during growth in medium containing $9 \%$ and $12 \%$ ethanol, respectively [29]. Therefore, these studies demonstrated that it is difficult to determine the microbial ethanol stress response mechanisms through limited proteins or pathways.

Mass spectrometry-based proteomics has allowed an in-depth view of the proteome and extensively contributed biological insights of underlying molecular mechanisms on a global level [30, 31]. iTRAQ-based quantitative proteomics has been applied to identify and quantify proteins from a variety of prokaryotic samples simultaneously [32, 33]. Therefore, iTRAQ-based quantitative proteomic approach was conducted to examine the molecular response of strain YUAN-3 to ethanol stress. This study contributes to the elucidation of metabolic regulation mechanisms in fermentative anaerobes and improves our understanding of the cross-feeding interactions among $\mathrm{H}_{2}$-utilizing, acetate- and ethanolconsuming species. These information are important to effectively shape the microbiome for biofuel and bioenergy production from waste stream.

\section{Results and discussion}

Ethanol stress facilitates ethanologenesis and growth of strain YUAN-3

There was a significant decrease in gas production rate. The maximum gas production rate decreased from 186.05 to $125.7 \mathrm{~mL}$ (L-culture $)^{-1} \mathrm{~h}^{-1}$ with increasing exogenous ethanol from 0 to $200 \mathrm{mM}$ (Fig. 1a). Moreover, the fermentation time was also prolonged from 62 to $80 \mathrm{~h}$ with increasing exogenous ethanol (Fig. 1a). There was a clear trend of decreasing hydrogen yield from $1888.6 \pm 45.8$ to $837 \pm 64.7 \mathrm{~mL} \mathrm{~L}^{-1}$ with increasing exogenous ethanol from 0 to $200 \mathrm{mM}$; however, the final cell dry weight of strain YUAN-3 increased in the presence of exogenous ethanol and the maximum cell dry weight reached $544 \pm 9.7 \mathrm{mg} \mathrm{L}^{-1}$ (Fig. 1b). The acetic acid yield of strain YUAN-3 significantly decreased from $1767.7 \pm 45$ to $160.6 \pm 44.7 \mathrm{mg} \mathrm{L}^{-1}$ in the presence 


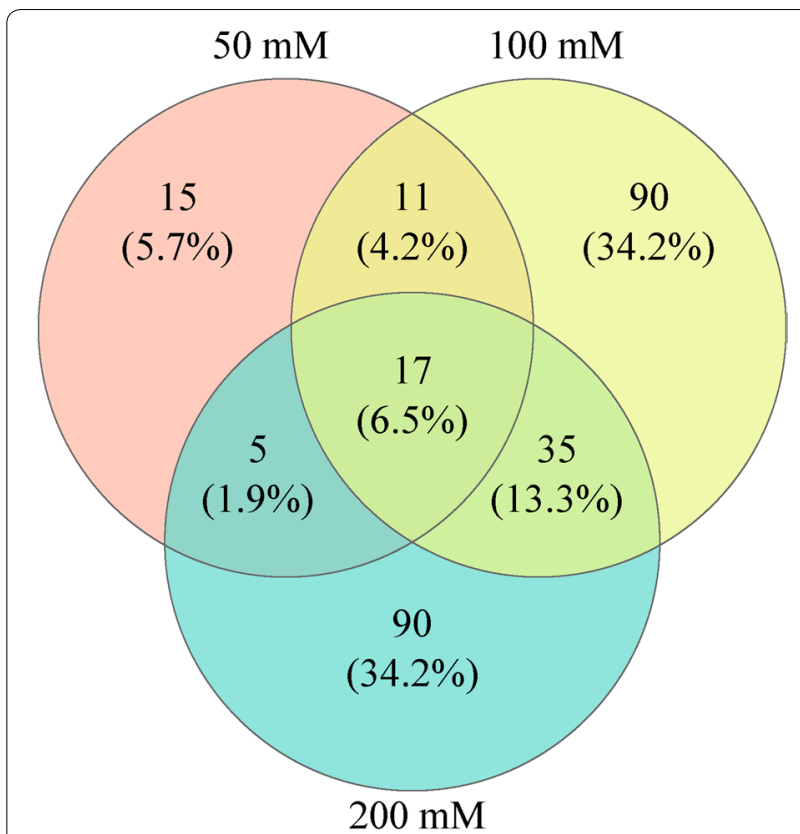

Fig. 2 Overlap of the differentially expressed proteins of strain YUAN-3 in 50 mM, 100 mM, and 200 mM ethanol stress, respectively

of exogenous ethanol (Fig. 1c); this trend positively correlates to the hydrogen yield and negatively correlates with the final cell dry weight of strain YUAN-3 as shown in Fig. 1b. Furthermore, the endogenous ethanol yield of strain YUAN-3 increased by $15.1 \%, 30.1 \%$, and $27.4 \%$ compared with control $(0 \mathrm{mM})$, when the culture was supplemented with exogenous ethanol of $50 \mathrm{mM}$, $100 \mathrm{mM}$, and $200 \mathrm{mM}$, respectively. The maximum yield of endogenous ethanol reached $4030.4 \pm 102.8 \mathrm{mg} \mathrm{L}^{-1}$ in the presence of $100 \mathrm{mM}$ exogenous ethanol (Fig. 1c). The molar ratios of endogenous ethanol to acetic acid were $2.29,5.88,10.52$, and 32.05 with increasing exogenous ethanol from $0 \mathrm{mM}$ to $200 \mathrm{mM}$, while the weight percentage of endogenous ethanol in liquid end-products (endogenous ethanol and acetic acid) increased from 63.7 to $96.1 \%(\mathrm{w} / \mathrm{w})$.

Exogenous ethanol reduced acetic acid and hydrogen production in strain YUAN-3. It could prevent a sharp decrease in $\mathrm{pH}$ of the medium due to acetic acid accumulation. Longer fermentation time will boost ethanol production in a continuous-flow reactor due to the mitigation of acidogenesis and substrate oxidation. However, the fermentation time of strain YUAN-3 was also prolonged by exogenous ethanol addition. Further work needs to be done, such as selecting better ethanol-tolerated strains of Ethanoligenens harbinense, improving the culture conditions to enhance the ethanol tolerance of strain YUAN-3.

\section{Identification of the differentially expressed proteins}

A total of 1680 proteins in strain YUAN-3 were identified in this study (62\% of the predicted proteins in YUAN-3 proteome). A total of 1527 proteins were accurately quantified and 263 differentially expressed proteins were identified. Proteins $(48,153$, and 147) were differentially expressed in the culture supplemented with exogenous ethanol of $50 \mathrm{mM}, 100 \mathrm{mM}$, and $200 \mathrm{mM}$, respectively (Additional file 1: Tables S1, S3). A Venn diagram result showed that 90 differentially expressed proteins were exclusively grouped in $100 \mathrm{mM}$ samples, which was also

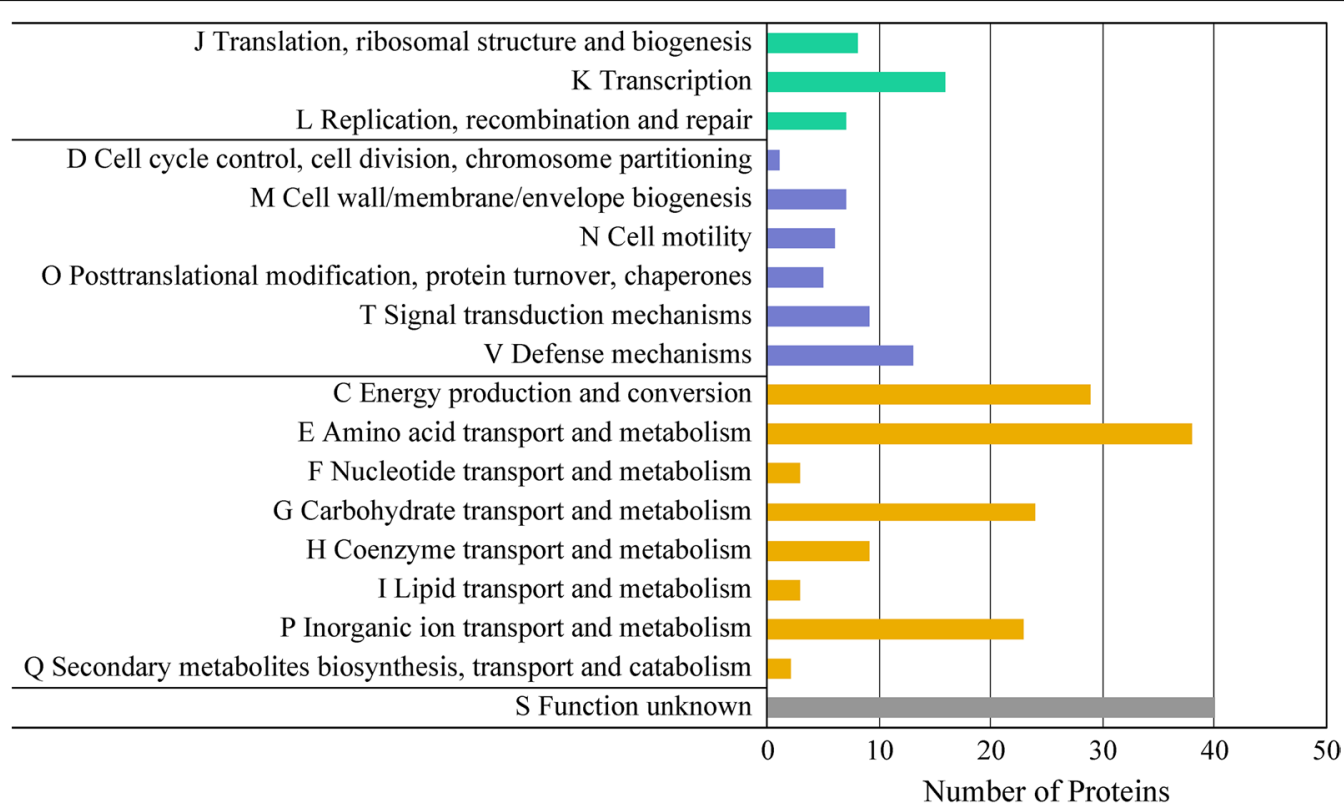

Fig. 3 Clusters of orthologous groups (COG) classification of the differentially expressed proteins in strain YUAN-3 


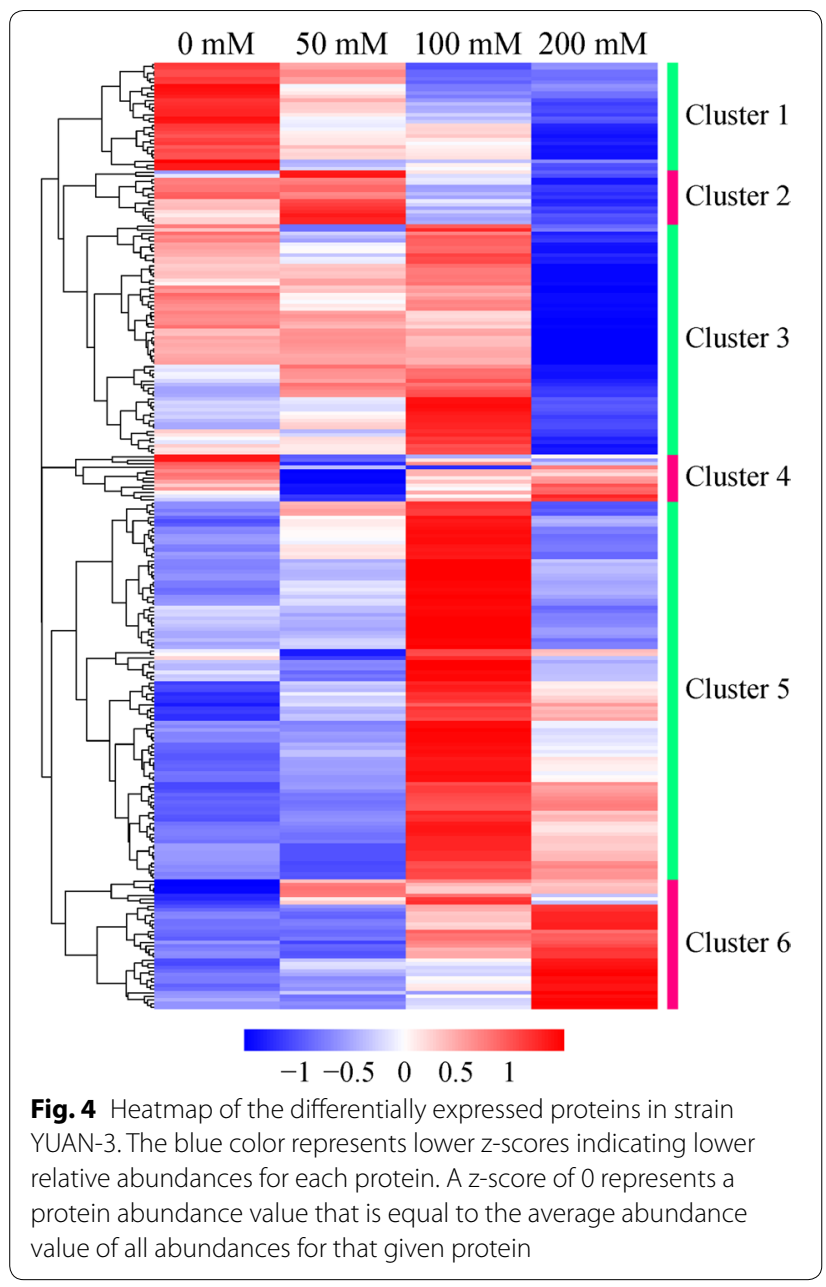

observed in the $200 \mathrm{mM}$ samples (Fig. 2). The 263 differentially expressed proteins were further categorized into 18 groups according to clusters of orthologous groups (COG) categorization (Fig. 3). These proteins were mainly grouped into several categories, namely, amino acid transport and metabolism (38 proteins), energy production and conversion (29 proteins), carbohydrate transport and metabolism (24 proteins), inorganic ion transport and metabolism (23 proteins), and transcription (16 proteins). Moreover, 40 proteins belong to the unknown function group, while 20 proteins share no significant similarity with any group.

\section{Functions of the differentially expressed proteins in ethanol stress}

The clustering analysis was performed based on similar expression profiles of proteins. The 263 differentially expressed proteins were classified into 6 major clusters and the result was displayed in a heatmap (Fig. 4). To understand the functions of these proteins better, all the proteins in each cluster were further analyzed according to the KEGG pathway enrichment. The results revealed that ethanol caused dramatic changes in the protein expression profiles of strain YUAN-3 (Additional file 1: Table S4). Thirty proteins were classified into cluster 1 ; these proteins were mainly involved in $A B C$ transporters, phosphotransferase system (PTS), fructose and mannose metabolism. The expression levels of proteins in cluster 1 were down-regulated in the presence of ethanol, thus indicating that the expression levels of these proteins were negatively related to the ethanol concentrations. Fifteen proteins were grouped in cluster 2 and the expression levels of most proteins in this cluster were down-regulated at $100 \mathrm{mM}$ exogenous ethanol concentration. The expression levels of proteins which participate in riboflavin metabolism (vitamin B2) in this cluster were up-regulated at $50 \mathrm{mM}$ exogenous ethanol concentration. Sixty-four proteins were classified into cluster 3; the expression levels of these proteins were down-regulated when the exogenous ethanol concentration reached $200 \mathrm{mM}$. Proteins in this cluster are mainly associated with oxidative phosphorylation, two-component system, and flagellar assembly. Thirteen proteins were grouped in cluster 4 . The expression levels of these proteins were down-regulated at $50 \mathrm{mM}$ exogenous ethanol concentration. The proteins in this cluster mainly participate in the phosphotransferase system (PTS). One hundred and five proteins were classified into cluster 5 and the expression levels of these proteins were elevated at $100 \mathrm{mM}$ exogenous ethanol concentration. Proteins in this cluster are mainly involved in histidine metabolism, biosynthesis of amino acids, biosynthesis of secondary metabolites, and glycolysis. Thirty-six proteins were grouped in cluster 6. The expression levels of most proteins in this cluster were up-regulated in the presence of ethanol. The expression levels of these proteins were positively related to the ethanol concentrations. Proteins in cluster 6 are mainly associated with microbial metabolism in diverse environments and nitrogen metabolism.

\section{Exogenous ethanol up-regulated ethanologenesis-related proteins}

Bifunctional acetaldehyde-CoA/alcohol dehydrogenase (ADHE) has been demonstrated to be a key enzyme in ethanol production. This enzyme contains two catalytic reaction domains which are responsible for the conversion of acetyl-coenzyme A to ethanol. The N-terminal acetaldehyde dehydrogenase (ALDH) domain of ADHE is responsible for the conversion of acetyl-CoA into acetaldehyde; while the $\mathrm{C}$-terminal alcohol dehydrogenase $(\mathrm{ADH})$ domain of $\mathrm{ADHE}$ is responsible for the conversion 


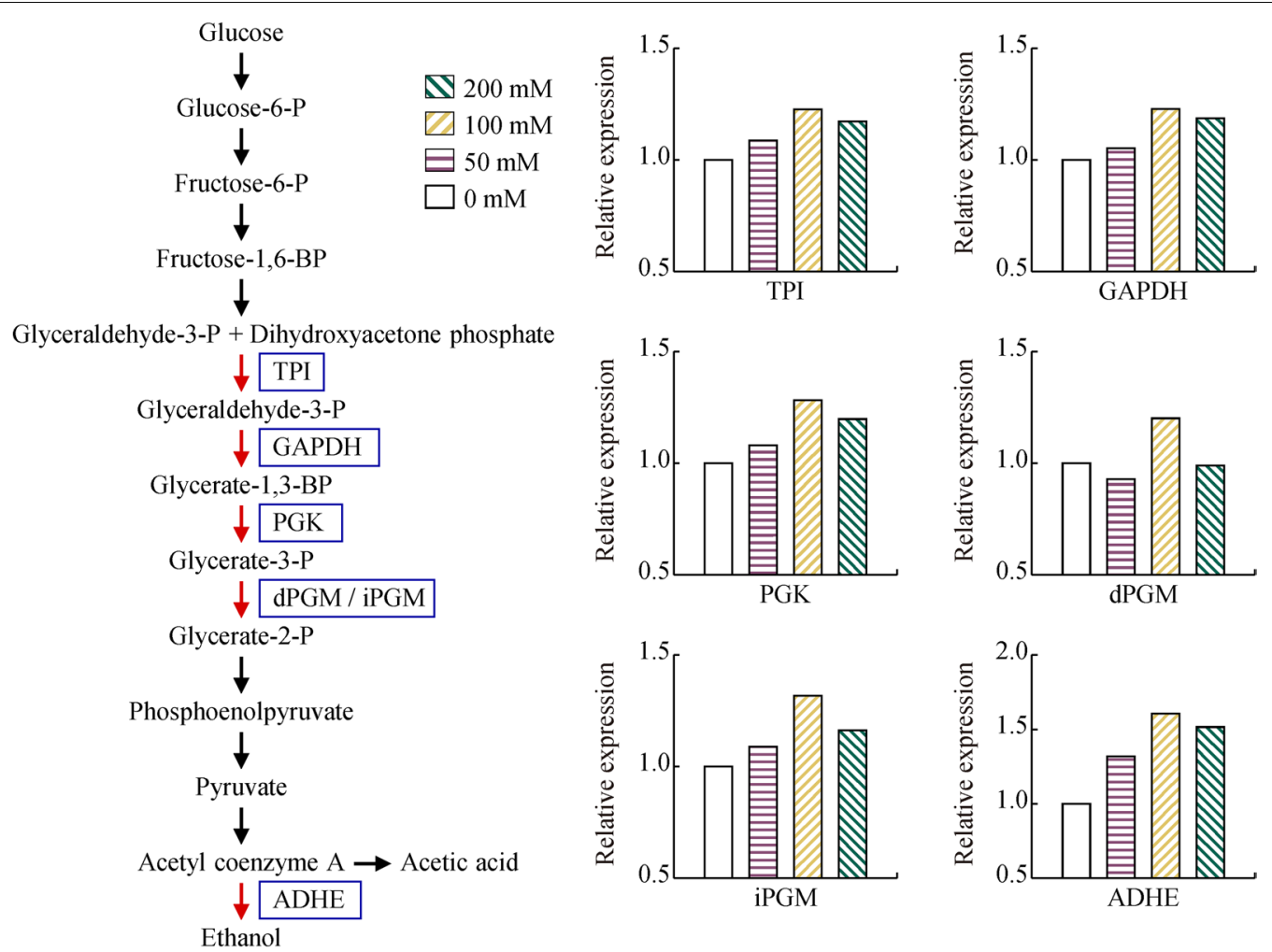

Fig. 5 The differentially expressed proteins involved in glycolysis and ethanol production of strain YUAN-3. TPI, triosephosphate isomerase; GAPDH, glyceraldehyde-3-phosphate dehydrogenase; PGK, phosphoglycerate kinase; dPGM, 2, 3-diphosphoglycerate-dependent phosphoglycerate mutase; iPGM, 2, 3-bisphosphoglycerate-independent phosphoglycerate mutase; ADHE, bifunctional acetaldehyde-CoA/alcohol dehydrogenase

of acetaldehyde to ethanol [34]. ADHE (ADU26923) of strain YUAN-3 was identified with 10,944 peptide-spectrum matches which is the second most numerous peptide-spectrum matches of all the identified proteins in strain YUAN-3. The data suggested that ADHE was one of the most abundant proteins in strain YUAN-3 (Additional file 1: Table S5). Surprisingly, we also found that ADHE exhibited 1.32-, 1.61-, and 1.52-fold change in the presence of $50 \mathrm{mM}, 100 \mathrm{mM}$, and $200 \mathrm{mM}$ exogenous ethanol, respectively. Thus, the expression level of ADHE was observed to be closely related to the endogenous ethanol yields that exhibited 1.15-, 1.30-, and 1.27-fold change, respectively (Figs. 1c and 5). This result clearly demonstrates that the endogenous ethanol yield of strain YUAN-3 increases when exogenous ethanol is added to the medium (Fig. 1c). Although ethanol yield of Ethanoligenens is lower than yeast, this genus can simultaneously produce ethanol of high purity $(96.1 \%, \mathrm{w} / \mathrm{w})$ and hydrogen gas. In contrast, yeast cannot produce hydrogen gas that has much higher combustion efficiency than ethanol. $\mathrm{H}_{2}$ and ethanol co-production makes this Ethanoligenens become a promising candidate for production of biofuel and bioenergy from wastewater.

In addition, the syntheses of ethanol and acetic acid in Ethanoligenens are acetyl-CoA-consuming reactions that directly compete for acetyl-CoA. On the other hand, the productions of ethanol and hydrogen gas are NADHconsuming reactions that compete for NADH. Therefore, increased yield of ethanol resulted in lower conversion of acetyl-CoA into acetic acid and also lower NADH for hydrogen production (Fig. 1b, c). This could explain why the yields of hydrogen gas and acetic acid declined even though expression levels of [FeFe]-hydrogenase $\left(\mathrm{H}_{2}\right.$ ase $)$ and acetate kinase did not show significant change correspondingly.

We found five enzymes related to the glycolysis pathway that were up-regulated at $100 \mathrm{mM}$ ethanol stress and grouped in cluster 5 (Figs. 4 and 5). These glycolytic enzymes include phosphoglycerate kinase (PGK, ADU27083), triosephosphate isomerase (TPI, ADU27084), glyceraldehyde-3-phosphate dehydrogenase (GAPDH, ADU28097), 2, 3-diphosphoglycerate-dependent phosphoglycerate mutase (dPGM, ADU26920), and 2, 3-bisphosphoglycerate-independent phosphoglycerate mutase (iPGM, ADU27085). 
Certain eubacteria possess both dPGM and iPGM, but dPGM has a tenfold higher specific activity than iPGM to catalyze the interconversion of 2-phosphoglycerate and 3-phosphoglycerate in glycolysis [35]. The expression levels of these glycolytic enzymes and the endogenous ethanol yield of strain YUAN-3 are tightly related (Fig. 1c). Accumulated evidence showed that cells must expend considerably high levels of energy to mitigate ethanol stress. Cells repair cellular macromolecules that were damaged in ethanol stress and employ efflux pumps for dealing with ethanol toxicity [36]. Therefore, the up-regulated expression levels of glycolytic enzymes in strain YUAN-3 suggest that ethanol stress increases the demand for energy to increase tolerance. In addition, increased expression levels of glycolytic enzymes in the presence of $100 \mathrm{mM}$ exogenous ethanol would contribute to the production of NADH and pyruvate which increases the production of ethanol in strain YUAN3 . This could explain why strain YUAN-3 achieved the highest endogenous ethanol yield in the presence of $100 \mathrm{mM}$ exogenous ethanol compared to other samples in this study (Fig. 1c).

Both ethanol synthesis and hydrogen production are $\mathrm{NADH}$-consuming reactions which further influence the cellular NADH/NAD ${ }^{+}$levels. The redox-sensing transcriptional repressor Rex plays a key role in sensing cellular NADH/NAD ${ }^{+}$levels and it negatively controls the transcription of a large variety of $\mathrm{NADH} / \mathrm{NAD}^{+}$-utilizing redox enzymes which influence the cellular NADH/ $\mathrm{NAD}^{+}$balance. Under the condition of low cellular $\mathrm{NADH} / \mathrm{NAD}^{+}$ratio, Rex binds to the target DNA sites and represses transcription of target genes [37]. Through comparative genomics approach analysis, results indicate that Rex target genes are mainly involved in energy metabolism, central carbohydrate metabolism, fermentation pathways, nitrate/nitrite and sulfate/sulfite reduction pathways, and $\mathrm{NAD}(\mathrm{P}) \mathrm{H}$ biogenesis pathways [38]. In addition, the novel function of Rex in the control of hydrogen production genes was validated in hydrogenproducing bacterium Thermotoga maritima [38]. In this study, we found the endogenous ethanol production yield of strain YUAN-3 increased; while the hydrogen product yield decreased in the presence of exogenous ethanol (Fig. 1b, c). According to iTRAQ analysis, the expression level of redox-sensing transcriptional repressor Rex (ADU26924) was up-regulated in the presence of $100 \mathrm{mM}$ exogenous ethanol (Additional file 1: Table S2). Thus, we speculate that the Rex-dependent regulation system regulates ethanologenesis and hydrogen production of strain YUAN-3, thus subsequently altering the yield of each end-product.

The cell dry weight of strain YUAN-3 increased in the presence of exogenous ethanol (Fig. 1b). An efficient biomass formation resulted into less amount of substrate transformed into end-products; thus, this result could partially explain why the yields of hydrogen gas and acetic acid declined in this study. More recently, the effect of ethanol on the global metabolic response in Oenococcus oeni was investigated using an extended genome-scale metabolic model. The results indicated that the requirements of $\mathrm{NAD}(\mathrm{P})^{+}$and ATP increased during ethanol stress. The strain required 10 and 17 times more nongrowth associated maintenance ATP during growth in medium containing $9 \%$ and $12 \%$ ethanol, respectively [29]. Therefore, the altered distribution of end-product yields in strain YUAN-3 indicates the need to redirect energy flow to maintain an efficient balance between ethanol stress response and growth.

\section{Proteins involved in carbon and nitrogen metabolism}

According to COG categorization, we observed that 38 proteins were involved in the group of amino acid transport and metabolism (Fig. 3), which has the highest number of differentially expressed proteins in strain YUAN-3 compared to other COG groups. This result is consistent with the response mechanism of Clostridium thermocellum ATCC27405 to ethanol stress, in which proteins related to nitrogen uptake and metabolism are most affected [39]. In addition, 24 proteins were found in the group of carbohydrate transport and metabolism (Fig. 3). These results indicated that carbon and nitrogen metabolism is a crucial process for dealing with ethanol stress in strain YUAN-3.

Proteins of strain YUAN-3 involved in nitrogen metabolism were differentially expressed in ethanol stress. Four proteins involved in urea cycle and metabolism were significantly up-regulated in $100 \mathrm{mM}$ ethanol stress. Two of these proteins were up-regulated in $50 \mathrm{mM}$ ethanol stress. These proteins were grouped into cluster 5 (Fig. 4 and Additional file 1: Tables S1, S2) including urea carboxylase (ADU27908), allophanate hydrolase (ADU27909), and urea carboxylase-associated protein (ADU27906 and ADU27907). A recent study has revealed that the urea carboxylase of Oleomonas sagaranensis can also use guanidine as substrates. Guanidine in bacteria can be degraded in the same manner as urea but the catalytic efficiency was observed to be 40 times better for guanidine than urea [40]. They also demonstrated that bacteria are capable of endogenously producing guanidine, which is the ligand of guanidine-I riboswitches and induces the expression of guanidine-I riboswitchmediated genes [40]. The guanidine-I riboswitches were reported to control the expression of a variety of transporter and metabolic genes, including genes annotated as urea carboxylases, urea carboxylase-associated protein, allophanate hydrolase, nitrate/sulfate/bicarbonate 
transporters, multidrug resistance transporters, and genes involved in nitrogen metabolism [41, 42]. We also identified two proteins (ADU27903 and ADU27905) of ABC-type nitrate/sulfonate/bicarbonate transport system that were up-regulated in $50 \mathrm{mM}$ and $100 \mathrm{mM}$ ethanol stress (Additional file 1: Tables S1, S2). Since urea was not provided as nitrogen source in the medium and homologue enzymes that catalyze arginine to ornithine and urea have not been identified in strain YUAN3 ; it is possible that ethanol stress increases the cellular concentration of guanidine in strain YUAN-3. Ethanol stress subsequently induces the expression of guanidine-I riboswitch-mediated genes.

The carbon storage regulator protein (CsrA) has been known to control a number of physiological processes such as central carbon metabolism, acetate metabolism, stress response, biofilm formation, flagellum biosynthesis, and peptide uptake [43]. It has been observed to positively regulate glycolysis, flagellum biosynthesis, and acetate metabolism [43, 44]. In this study, the expression level of CsrA (ADU28042) was down-regulated in the presence of $200 \mathrm{mM}$ ethanol stress (Additional file 1: Table S3). Since CsrA positively regulates glycolysis, decreased expression of CsrA would result in the

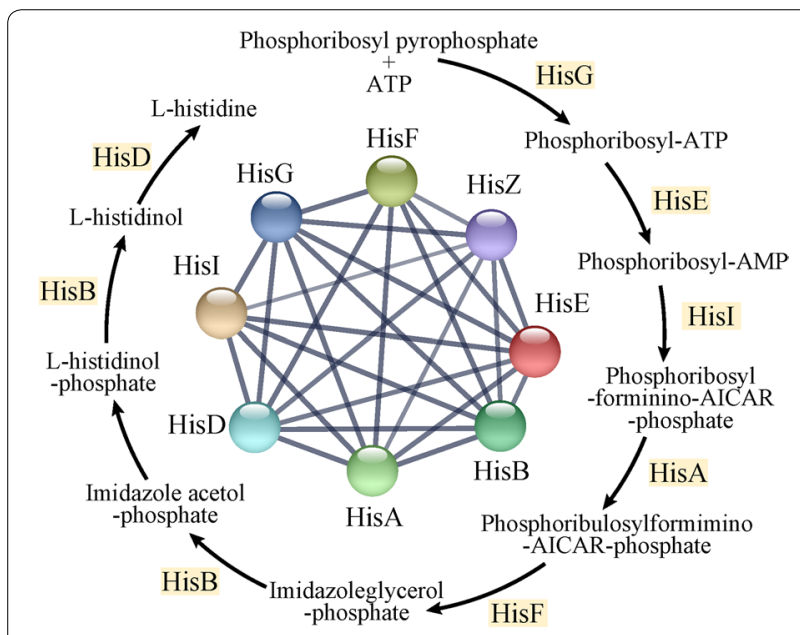

Fig. 6 Protein-protein interaction network of the differentially expressed proteins involved in histidine biosynthesis in strain YUAN-3. The network nodes are proteins; the thickness of the network line indicate the degree of confidence prediction of the interaction. The minimum required interaction score is 0.4 . AICAR, 5'-phosphoribosyl-4-carboxamide-5-aminoimidazole; HisG, ATP phosphoribosyltransferase; HisE, phosphoribosyl-ATP pyrophosphatase; Hisl, phosphoribosyl-AMP cyclohydrolase; HisA, 1-(5-phosphoribosyl)-5-[(5-phosphoribosylamino) methylideneamino] imidazole-4-carboxamide isomerase; HisF, imidazole glycerol phosphate synthase subunit; HisB, imidazoleglycerol-phosphate dehydratase; HisD, histidinol dehydrogenase; HisZ, ATP phosphoribosyltransferase regulatory subunit repression of glycolysis. The result could partially explain why the batch fermentation time of strain YUAN-3 was longer in $200 \mathrm{mM}$ ethanol stress than other samples (Fig. 1a). Six proteins involved in flagellum biosynthesis including flagellar motor protein MotA (ADU28031), flagellar export chaperone FliS (ADU28033), flagellin (ADU28041), flagellar motor protein MotP (ADU28061), flagellar hook-basal body protein (ADU28063), and flagellar protein export ATPase FliI (ADU28068) were also down-regulated in $200 \mathrm{mM}$ ethanol stress (Additional file 1: Table S3). These proteins and CsrA belong to cluster 3 (Fig. 4). These results support previous studies that CsrA positively regulates flagellum biosynthesis. Furthermore, CsrA is also associated with the stress response. The CsrA of Clostridium beijerinckii NCIMB 8052 was reported significantly repressed in furfural stress [45]. Thus, the results of this study also suggest that CsrA plays an important role in ethanol stress response.

\section{Proteins involved in the tolerance of ethanol stress}

In this study, we observed that two oxidative stress response proteins were induced during ethanol stress, which includes desulfoferrodoxin (ADU28196) and glutathione peroxidase (ADU28264) (Additional file 1: Tables S2, S3). Desulfoferrodoxin has been reported to function as a superoxide reductase (SOR) and superoxide dismutase (SOD), which protects anaerobic bacteria from oxidative stress [46, 47]. Through DNA microarray analysis, the result has shown that desulfoferrodoxin gene expression of Clostridium acetobutylicum was upregulated in butanol, butyrate, and acetate stress [48]. The main biological role of glutathione peroxidase is to protect the organism from oxidative stress. Previous research has reported that glutathione peroxidase of Lactobacillus plantarum WCFS1 was induced during growth while exposed to ethanol stress [49]. In this study, desulfoferrodoxin of strain YUAN-3 was found to be upregulated in $100 \mathrm{mM}$ and $200 \mathrm{mM}$ ethanol stress; while glutathione peroxidase was up-regulated in $100 \mathrm{mM}$ ethanol stress. These results indicate new potential protective roles of desulfoferrodoxin and glutathione peroxidase in ethanol stress response.

Eight proteins of strain YUAN-3 involved in histidine biosynthesis were also identified to be up-regulated in $100 \mathrm{mM}$ ethanol stress; three of these proteins were up-regulated in $200 \mathrm{mM}$ ethanol stress (Fig. 6 and Additional file 1: Tables S2, S3). These proteins belong to cluster 5 (Additional file 1: Table S4), including HisE (ADU26970), HisI1 (ADU26971), HisF (ADU26972), HisA (ADU26973), HisB (ADU26975), HisD (ADU26977), HisG (ADU26978), and HisZ (ADU26979). It has been shown that increased expression of genes for histidine biosynthesis contributes to acid tolerance 
in Lactobacillus casei. The strain displayed a 100-fold increase in survival after exogenous addition of histidine to the medium during acid stress [50]. Nine histidine biosynthesis genes of Clostridium acetobutylicum were up-regulated in butanol and butyrate stress [51]. Up-regulation of histidine biosynthesis genes was also observed in ethanol tolerant Escherichia coli strains [52]. Therefore, it is plausible that histidine biosynthesis elevates the ethanol tolerance of strain YUAN-3.

\section{Perspective and outlook}

Proteins directly participate in the biological processes and functions; thus, the quantitative proteomic analysis can provide direct evidences for the regulation mechanisms of physiology and metabolism at global level [53]. Because the correlation between transcriptome (mRNA) and proteome is often low, quantitative proteomic analysis becomes especially important to reveal the regulation mechanism of biological processes [54]. This study gave an example to reveal the regulation of $\mathrm{H}_{2}$-ethanol fermentative metabolism based on quantitative proteomic analysis, and the experimental protocol can be used to investigate the metabolic regulation and function of other microbes. These results indicated that the protein regulation of anaerobes was complicated and interactive. Biological processes usually involve multiple proteins, the amount and variety of these proteins are unknown. Therefore, it is difficult to reveal the mechanism of metabolic regulation through conventional approach that focuses on single or few target proteins. The hydrogenase expression level showed no significant change even if hydrogen production changed in strain YUAN-3. The regulation of hydrogen production may be directly dependent upon the activity of hydrogenase, and the upstream proteins responsible for electron transfer and NADH generation in hydrogen production pathway. Besides, further investigations need to be done on protein post-translational modification and protein-protein interaction of the enzymes which were not significantly changed.

\section{Conclusions}

Exogenous ethanol altered the yields of end-products in $E$. harbinense strain YUAN-3. Ethanol stress enhanced ethanol production and also inhibited the production of hydrogen gas and acetic acid. Differentially expressed proteins $(48,153$, and 147) were identified in $50 \mathrm{mM}$, $100 \mathrm{mM}$, and $200 \mathrm{mM}$ ethanol stress, respectively. These proteins are mainly involved in central carbon metabolism, amino acid transport and metabolism, and oxidative stress response. The distribution of end-product yields was altered during ethanol stress in strain YUAN-3 due to the up-regulation of ethanologenesis-related proteins by exogenous ethanol. The differentially expressed proteins also corresponded to metabolic changes necessary to the growth and survival of $E$. harbinense YUAN-3 during ethanol stress. This study also provided a new approach to change the pattern of end-products and enhance ethanol production by Ethanoligenens harbinense through exogenous ethanol addition. This approach can be easily employed via the circulation of liquid end-products in a continuous-flow anaerobic bioreactor. Ethanoligenens has been identified as a predominant population in ethanol-type fermentation, which becomes one of the representative hydrogen-producing genera. Therefore, the ethanol production in ethanol-type fermentation of mixed cultures could be enhanced through this approach. However, this regulatory strategy must be further verified in the continuous-flow anaerobic bioreactors.

\section{Methods}

\section{Culture conditions}

Ethanoligenens harbinense strain YUAN-3 was cultivated in anaerobic PYG medium at $35{ }^{\circ} \mathrm{C}$ with initial $\mathrm{pH}$ value of 7 . The composition of $1 \mathrm{~L}$ PYG medium include glucose $10 \mathrm{~g}$, peptone $4 \mathrm{~g}$, yeast extract $1 \mathrm{~g}, \mathrm{NaCl} 4 \mathrm{~g}$, $\mathrm{K}_{2} \mathrm{HPO}_{4} 1.5 \mathrm{~g}, \mathrm{MgCl} \cdot 6 \mathrm{H}_{2} \mathrm{O} 0.1 \mathrm{~g}$, and L-cysteine $0.24 \mathrm{~g}$. Mineral salt solution and vitamin solution were added according to the previous description [55]. In the experiment investigating effect of ethanol stress on end-products and cell dry weight of strain YUAN-3, $4 \mathrm{~mL}(2 \%, \mathrm{v} / \mathrm{v})$ of logarithmic stage YUAN-3 culture was used to inoculate into $200-\mathrm{mL}$ medium. Different final concentrations $(50,100,200 \mathrm{mM})$ of exogenous ethanol were added to the medium before the experiment. The medium without ethanol served as the control.

\section{End-products and accumulated biomass analysis}

Challenge AER-208 Aerobic/Anaerobic Respirometer System (Challenge Environmental System, Arkansas) was used to investigate the gas yield and production rate of strain YUAN-3. $\mathrm{H}_{2}, \mathrm{CO}_{2}$, alcohols, volatile fatty acids and biomass were analyzed after the fermentation process ended. $\mathrm{H}_{2}$ and $\mathrm{CO}_{2}$ were determined using gas chromatograph (Agilent GC7890A, USA) equipped with thermal conductivity detector, while alcohols and volatile fatty acids were analyzed via gas chromatography (Agilent GC7890A, USA) equipped with flame ionization detector [56]. All the ethanol in each YUAN-3 culture was analyzed by gas chromatography, respectively; the endogenous ethanol yields were calculated by deducting the amount of exogenous ethanol. For cell dry weight measurement, YUAN-3 cultures were centrifuged at $10,000 \times g$ for $10 \mathrm{~min}$ at $4{ }^{\circ} \mathrm{C}$. The pellets were washed twice in PBS buffer and dried at $105^{\circ} \mathrm{C}$. 


\section{Sample preparation and protein extraction for proteomic analysis}

To guarantee that ethanol is the single factor that affects metabolism of strain YUAN-3, the medium of YUAN-3 culture in logarithmic stage $(100 \mathrm{~mL})$ was removed by centrifugation at $10,000 \times g$ for $5 \mathrm{~min}$; the YUAN-3 pellets were immediately transferred to $200-\mathrm{mL}$ fresh medium with exogenous ethanol at anaerobic conditions. Exogenous ethanol was supplemented to the medium at different final concentrations $0,50,100$, and $200 \mathrm{mM}$, respectively. The YUAN-3 culture was cultivated at $35^{\circ} \mathrm{C}$ for $2 \mathrm{~h}$ and collected by centrifugation $(10,000 \times g, 5 \mathrm{~min})$ at $4{ }^{\circ} \mathrm{C}$. There were $2.92,2.99,3.36,3.55 \mathrm{mM}$ (134.7, $137.6,154.9,163.3 \mathrm{mg} \mathrm{L}^{-1}$ ) ethanol endogenously generated by strain YUAN-3 at $2 \mathrm{~h}$ with increasing exogenous ethanol from $0 \mathrm{mM}$ to $200 \mathrm{mM}$, respectively, which were trace amount compared with the exogenous ethanol, and can be neglected in this study. The pellets were washed twice with chilled anaerobic PBS buffer ( $\mathrm{pH}$ 7.4, $\mathrm{NaCl} 137 \mathrm{mM}, \mathrm{KCl} 2.7 \mathrm{mM}, \mathrm{Na}_{2} \mathrm{HPO}_{4} 10 \mathrm{mM}, \mathrm{KH}_{2} \mathrm{PO}_{4}$ $2 \mathrm{mM}$ ). FastPrep-24 instrument (MP Biomedical) was used for homogenization; $30 \mathrm{mg}$ sample was transferred to lysing matrix B tubes with $500 \mu \mathrm{L}$ chilled Tris $\mathrm{pH} 8.8$ buffered phenol (Sigma) and $500 \mu \mathrm{L}$ chilled extraction buffer. The samples were homogenized twice for $40 \mathrm{~s}$ and chilled on ice for $3 \mathrm{~min}$ between each cycle. The extraction buffer contained $0.1 \mathrm{M}$ Tris- $\mathrm{HCl}(\mathrm{pH} 8.8), 10 \mathrm{mM}$ EDTA, $0.9 \mathrm{M}$ sucrose, $0.4 \%(\mathrm{v} / \mathrm{v})$ 2-mercaptoethanol, and $1 \%(\mathrm{v} / \mathrm{v})$ protease inhibitor cocktail (set II, Calbiochem). The following steps were performed according to phenol extraction method as previously described [57].

\section{Protein digestion and ITRAQ labeling}

The biological duplicate protein samples $(0.75 \mathrm{mg})$ were reconstituted in $150 \mu \mathrm{L} 1 \times \mathrm{LDS}$ (Invitrogen) with $50 \mathrm{mM}$ DTT (dithiothreitol), followed by incubation at $90{ }^{\circ} \mathrm{C}$ for $10 \mathrm{~min}$. Ten percent of each sample were loaded and run into SDS-PAGE gel. The in-gel protein samples were reduced with $10 \mathrm{mM}$ DTT at $60^{\circ} \mathrm{C}$ for $30 \mathrm{~min}$ and alkylated with $20 \mathrm{mM}$ iodoacetamide at room temperature and dark conditions for $1 \mathrm{~h}$. The samples were digested overnight with trypsin (1/50, w/w, trypsin/sample) at $37{ }^{\circ} \mathrm{C}$. The digested peptides were subsequently extracted from the SDS-PAGE gel with buffer $(60 \%$ acetonitrile, $5 \%$ formic acid) and vacuum-dried to remove residual amine from the reagents. Peptides were labeled with iTRAQ 4-plex Kit (ABSciex, USA) according to the manufacturer's protocol and then combined after labeling.

\section{Nano-LC-MS/MS and bioinformatics analysis}

The Nano-LC-MS/MS analysis was carried out using a Dionex RSLC system coupled to Q-Exactive HF mass spectrometer (ThermoFisher, San Jose, CA). The prepared samples were dissolved in $0.1 \%$ trifluoroacetic acid and loaded into a home-made trap $(100 \mu \mathrm{m} \times 2 \mathrm{~cm}$, packed with Magic C18AQ, $5 \mu \mathrm{m}, 200 \AA$ pore size: Michrom Bioresources, Inc., Auburn, CA). Solvent A $(0.2 \%$ formic acid) was used to wash the samples at a flow rate of $10 \mu \mathrm{L} \mathrm{min}{ }^{-1}$ for $5 \mathrm{~min}$. The trap column was then connected to a homemade analytical column (Magic C18AQ, $3 \mu \mathrm{m}, 200 \AA$ pore, $75 \mu \mathrm{m} \times 50 \mathrm{~cm}$ ). Peptide fractions were separated at a flow rate of $300 \mathrm{~nL} \mathrm{~min}{ }^{-1}$ using a multi-stepped gradient of solvent B $(0.16 \%$ formic acid and $80 \%$ acetonitrile): $4-15 \%$ solvent $B$ for $25 \mathrm{~min}$, $15-25 \%$ solvent B for 65 min, $25-50 \%$ solvent B for $55 \mathrm{~min}$. The data-dependent acquisition procedure was performed to acquire mass spectrometry data. A full MS survey scan was recorded in the Orbitrap MS at a resolution of 120,000. The twenty most intense ions were isolated and analyzed subsequently in the Orbitrap at a resolution of 30,000. The relative collision energy was set to $30 \%$ in the HCD and dynamic exclusion duration was employed for $30 \mathrm{~s}$ during the subsequent MS/MS scans.

The Nano-LC-MS/MS data were searched in MUDPIT style against the protein database of Ethanoligenens harbinense YUAN-3 (http://bacteria.ensembl.org/Ethanolige nens_harbinense_yuan_3/Info/Index/; genome assembly: ASM17811v2) using an inhouse version of X!Tandem Sledgehammer (http://www.thegpm.org/tandem). The search parameters include the following: carbamidomethylation on cysteine and iTRAQ 4-plex label on lysine as fixed modifications, while iTRAQ 4-plex label on $\mathrm{N}$-terminus of peptides and oxidation of methionine served as variable modification. Tolerance for precursor was $\pm 7 \mathrm{ppm}$ and product ions was $20 \mathrm{ppm}$ and false discovery rate $(\mathrm{FDR}) \leq 1 \%$. Intensity of iTRAQ 4 -plex reporter ions of each spectrum was extracted by inhouse Perl script and corrected for isotope cross-over according to the values supplied by manufacturer. The ratio between samples was calculated based on reporter ion intensity and normalized to ratio of summed ion intensity of all identified spectra that fit certain criteria: peptides has iTRAQ 4-plex label, peptide belongs to Ethanoligenens harbinense YUAN-3 protein database, peptide $\log (e) \leq-2.0$. Spectra that have ratio as "Divide 0" were replaced with an arbitrary number " 10 ". Pairwise median ratios of individual protein were calculated by "Doby" package under $\mathrm{R}$ environment using all spectra belonging to a protein that fit the criteria described above plus the requirement that the sum of reporter ion intensity of both channels $>20,000$. Peptide-spectrum matches $\geq 3$ and $P \leq 0.01$ were required for protein quantitation.

The differentially expressed proteins were defined according to previous studies (fold change of $\leq 0.83$ for 
down-regulated proteins, $\geq 1.2$ for up-regulated proteins) and manually annotated through NCBI non-redundant protein sequences database (https://blast.ncbi.nlm.nih. gov/Blast.cgi?PROGRAM=blastp\&PAGE_TYPE=Blast Search\&LINK_LOC=blasthome) and UniProt protein database (https://www.uniprot.org/blast/) with local BLAST programs ( $E$-value $\leq 1.0 \mathrm{E}-5)$ [53, 58]. The heatmap was generated using the pheatmap package of version 3.2.3 on the R statistical platform (https:// CRAN.R-project.org/package=pheatmap) KEGG database and KOBAS 3.0 (http://kobas.cbi.pku.edu.cn/) were used to carried out the pathway enrichment of the differentially expressed proteins; pathways with $P$ value of $\leq 0.05$ were considered significantly enriched [59]. The protein-protein interaction analysis was conducted with STRING database of version 10.5 (http://string-db.org).

\section{Additional file}

Additional file 1: Table S1. The differentially expressed proteins of strain YUAN-3 in 50 mM ethanol stress. Table S2. The differentially expressed proteins of strain YUAN-3 in $100 \mathrm{mM}$ ethanol stress. Table S3. The differentially expressed proteins of strain YUAN-3 in 200 mM ethanol stress. Table S4. KEGG pathway enrichment of the differentially expressed proteins in strain YUAN-3. Table S5. The ten most numerous peptidespectrum matches of all the identified proteins in strain YUAN-3.

\section{Abbreviations}

ITRAQ: isobaric tags for relative and absolute quantification; BES: bioelectrochemical systems; MCFAs: medium-chain fatty acids; ABE-fermenting bacteria: acetone-butanol-ethanol-fermenting bacteria; COG: clusters of orthologous groups; PTS: phosphotransferase system; ADHE: bifunctional acetaldehydeCOA/alcohol dehydrogenase; ALDH: acetaldehyde dehydrogenase; ADH: alcohol dehydrogenase; PGK: phosphoglycerate kinase; TPI: triosephosphate isomerase; GAPDH: glyceraldehyde-3-phosphate dehydrogenase; $\mathrm{dPGM}$ : 2, 3-diphosphoglycerate-dependent phosphoglycerate mutase; iPGM: 2, 3-bisphosphoglycerate-independent phosphoglycerate mutase; CsrA: carbon storage regulator protein; AICAR: 5'-phosphoribosyl-4-carboxamide5-aminoimidazole; HisG: ATP phosphoribosyltransferase; HisE: phosphoribosyl-ATP pyrophosphatase; Hisl: phosphoribosyl-AMP cyclohydrolase; HisA: 1-(5-phosphoribosyl)-5-[(5-phosphoribosylamino) methylideneamino] imidazole-4-carboxamide isomerase; HisF: imidazole glycerol phosphate synthase subunit; HisB: imidazoleglycerol-phosphate dehydratase; HisD: histidinol dehydrogenase: HisZ: ATP phosphoribosyltransferase regulatory subunit: EDTA: ethylenediaminetetraacetic acid; DTT: dithiothreitol; SDS-PAGE: sodium dodecyl sulfate-polyacrylamide gel electrophoresis; FDR: false discovery rate.

\section{Acknowledgements}

This study was supported by the National Natural Science Foundation of China (No. 31870114), the National Key Research and Development Program of China (No. 2018YFD1 100503), and the State Key Laboratory of Urban Water Resource and Environment (Harbin Institute of Technology) (No. HCK201018).

\section{Authors' contributions}

DX and HL designed the experiment; HL performed specific experiments; $\mathrm{HL}$, $X M, G X, N R$, and DX contributed to analyze the experiment data; HL and DX wrote the manuscript. All authors were involved in revision of the manuscript. All authors read and approved the final manuscript.

\section{Funding}

National Natural Science Foundation of China (No. 31870114), State Key Laboratory of Urban Water Resources and Environment (Harbin Institute of Technology) (No. HCK201018).

\section{Availability of data and materials}

The datasets used and/or analyzed during the current study are available from the corresponding author on reasonable request.

Ethical approval and consent to participate

Not applicable.

\section{Consent for publication}

Not applicable.

\section{Competing interests}

The authors declare that they have no competing interests.

Received: 19 April 2019 Accepted: 19 June 2019

Published online: 28 June 2019

\section{References}

1. Meng F, Yang A, Wang H, Zhang G, Li X, Zhang Y, et al. One-step treatment and resource recovery of high-concentration non-toxic organic wastewater by photosynthetic bacteria. Bioresour Technol. 2018:251:121-7.

2. Ju F, Zhang T. Bacterial assembly and temporal dynamics in activated sludge of a full-scale municipal wastewater treatment plant. ISME J. 2015;9:683.

3. Frijns J, Hofman J, Nederlof M. The potential of (waste) water as energy carrier. Energy Convers Manage. 2013;65:357-63.

4. Morris BE, Henneberger R, Huber H, Moiss-Eichinger C. Microbial syntrophy: interaction for the common good. FEMS Microbiol Rev. 2013;37:384-406.

5. Greening C, Biswas A, Carere CR, Jackson CJ, Taylor MC, Stott MB, et al. Genomic and metagenomic surveys of hydrogenase distribution indicate $\mathrm{H}_{2}$ is a widely utilised energy source for microbial growth and survival. ISME J. 2016;10:761.

6. Constant P, Chowdhury SP, Pratscher J, Conrad R. Streptomycetes contributing to atmospheric molecular hydrogen soil uptake are widespread and encode a putative high-affinity [NiFe]-hydrogenase. Environ Microbiol. 2010;12:821-9.

7. Greening C, Carere CR, Rushton-Green R, Harold LK, Hards K, Taylor MC, et al. Persistence of the dominant soil phylum Acidobacteria by trace gas scavenging. Proc Natl Acad Sci USA. 2015;112:10497-502.

8. Xing D, Ren N, Li Q, Lin M, Wang A, Zhao L. Ethanoligenens harbinense gen. nov., sp. nov., isolated from molasses wastewater. Int J Syst Evol Microbiol. 2006:56:755-60.

9. Xing D, Ren N, Rittmann BE. Genetic diversity of hydrogen-producing bacteria in an acidophilic ethanol- $\mathrm{H}_{2}$-coproducing system, analyzed using the [Fe]-hydrogenase gene. Appl Environ Microbiol. 2008;74:1232.

10. Ren $N$, Xing D, Rittmann BE, Zhao L, Xie T, Zhao X. Microbial community structure of ethanol type fermentation in bio-hydrogen production. Environ Microbiol. 2007;9:1112-25.

11. Xing D, Ren N, Wang A, Li Q, Feng Y, Ma F. Continuous hydrogen production of auto-aggregative Ethanoligenens harbinense YUAN-3 under nonsterile condition. Int J Hydrogen Energy. 2008;33:1489-95.

12. Lu L, Ren N, Xing D, Logan BE. Hydrogen production with effluent from an ethanol- $\mathrm{H}_{2}$-coproducing fermentation reactor using a single-chamber microbial electrolysis cell. Biosens Bioelectron. 2009;24:3055-60.

13. Christy PM, Gopinath LR, Divya D. A review on anaerobic decomposition and enhancement of biogas production through enzymes and microorganisms. Renew Sust Energ Rev. 2014;34:167-73.

14. Carballa M, Regueiro L, Lema JM. Microbial management of anaerobic digestion: exploiting the microbiome-functionality nexus. Curr Opin Biotechnol. 2015:33:103-11.

15. Grootscholten T, Strik D, Steinbusch K, Buisman C, Hamelers H. Two-stage medium chain fatty acid (MCFA) production from municipal solid waste and ethanol. Appl Energy. 2014;116:223-9. 
16. Grootscholten T, Steinbusch K, Hamelers H, Buisman C. Chain elongation of acetate and ethanol in an upflow anaerobic filter for high rate MCFA production. Bioresour Technol. 2013;135:440-5.

17. Smits WK, Kuipers OP, Veening JW. Phenotypic variation in bacteria: the role of feedback regulation. Nat Rev Microbiol. 2006:4:259.

18. Thomas E. How to live at very low substrate concentration. Water Res. 2010:44:4826-37.

19. Abubackar HN, Bengelsdorf FR, Dürre P, Veiga MC, Kennes C. Improved operating strategy for continuous fermentation of carbon monoxide to fuel-ethanol by clostridia. Appl Energy. 2016;169:210-7.

20. Whitham JM, Tirado Acevedo O, Chinn MS, Pawlak JJ, Grunden AM. Metabolic response of Clostridium ljungdahlii to oxygen exposure. Appl Environ Microbiol. 2015;81:8379-91.

21. Liao C, Seo S-O, Celik V, Liu H, Kong W, Wang Y, et al. Integrated, systems metabolic picture of acetone-butanol-ethanol fermentation by Clostridium acetobutylicum. Proc Natl Acad Sci USA. 2015;112:8505-10.

22. Serrazanetti DI, Ndagijimana M, Sado-Kamdem SL, Corsetti A, Vogel RF, Ehrmann M, et al. Acid stress-mediated metabolic shift in Lactobacillus sanfranciscensis LSCE1. Appl Environ Microbiol. 2011;77:2656-66.

23. Li H, Mei X, Liu B, Li Z, Wang B, Ren N, et al. Insights on acetate-ethanol fermentation by hydrogen-producing Ethanoligenens under acetic acid accumulation based on quantitative proteomics. Environ Int. 2019;129:1-9.

24. Stephanopoulos G. Challenges in engineering microbes for biofuels production. Science. 2007;315:801-4.

25. Soufi B, Krug K, Harst A, Macek B. Characterization of the E. coli proteome and its modifications during growth and ethanol stress. Front Microbiol. 2015;6:103.

26. Zingaro KA, Nicolaou SA, Papoutsakis ET. Dissecting the assays to assess microbial tolerance to toxic chemicals in bioprocessing. Trends Biotechnol. 2013;31:643-53.

27. Huffer S, Clark ME, Ning JC, Blanch HW, Clark DS. Role of alcohols in growth, lipid composition, and membrane fluidity of yeasts, bacteria, and archaea. Appl Environ Microbiol. 2011;77:6400-8.

28. Haft RJ, Keating DH, Schwaegler T, Schwalbach MS, Vinokur J, Tremaine M, et al. Correcting direct effects of ethanol on translation and transcription machinery confers ethanol tolerance in bacteria. Proc Natl Acad Sci USA. 2014:111:2576-85.

29. Contreras A, Ribbeck M, Gutiérrez GD, Cañon PM, Mendoza SN, Agosin E. Mapping the physiological response of Oenococcus oeni to ethanol stress using an extended genome-scale metabolic model. Front Microbiol. 2018:9:291.

30. Altelaar AM, Munoz J, Heck AJ. Next-generation proteomics: towards an integrative view of proteome dynamics. Nat Rev Genet. 2013;14:35.

31. Aebersold R, Mann M. Mass-spectrometric exploration of proteome structure and function. Nature. 2016;537:347.

32. Raut MP, Couto N, Pham TK, Evans C, Noirel J, Wright PC. Quantitative proteomic analysis of the influence of lignin on biofuel production by Clostridium acetobutylicum ATCC 824. Biotechnol Biofuels. 2016;9:113.

33. Mertins P, Udeshi ND, Clauser KR, Mani DR, Patel J, Ong SE, et al. iTRAQ labeling is superior to MTRAQ for quantitative global proteomics and phosphoproteomics. Mol Cell Proteom. 2012;11 (M111):014423.

34. Olson DG, Sparling R, Lynd LR. Ethanol production by engineered thermophiles. Curr Opin Biotechnol. 2015;33:130-41.

35. Fraser $\mathrm{HI}$, Kvaratskhelia M, White MF. The two analogous phosphoglycerate mutases of Escherichia coli. FEBS Lett. 1999;455:344-8.

36. Nicolaou SA, Gaida SM, Papoutsakis ET. A comparative view of metabolite and substrate stress and tolerance in microbial bioprocessing: from biofuels and chemicals, to biocatalysis and bioremediation. Metab Eng. 2010;12:307-31.

37. Mclaughlin KJ, Strain-Damerell CM, Xie K, Brekasis D, Soares AS, Paget MSB, et al. Structural basis for NADH/NAD redox sensing by a rex family repressor. Mol Cell. 2010;38:563-75.

38. Ravcheev DA, Li X, Latif H, Zengler K, Leyn SA, Korostelev YD, et al. Transcriptional regulation of central carbon and energy metabolism in bacteria by redox-responsive repressor Rex. J Bacteriol. 2012;194:1145.

39. Yang S, Giannone RJ, Lezlee D, Yang ZK, Engle NL, Tschaplinski TJ, et al. Clostridium thermocellum ATCC27405 transcriptomic, metabolomic and proteomic profiles after ethanol stress. BMC Genomics. 2012;13:336.
40. Nelson JW, Atilho RM, Sherlock ME, Stockbridge RB, Breaker RR. Metabolism of free guanidine in bacteria is regulated by a widespread riboswitch class. Mol Cell. 2017;65:220-30.

41. Sherlock ME, Malkowski SN, Breaker RR. Biochemical validation of a third guanidine riboswitch class in bacteria. Biochemistry. 2016;56:359-63.

42. Breaker RR, Atilho RM, Malkowski SN, Nelson JW, Sherlock ME. The biology of free guanidine as revealed by riboswitches. Biochemistry. 2017;56:345.

43. Timmermans J, Van ML. Post-transcriptional global regulation by CsrA in bacteria. Cell Mol Life Sci. 2010;67:2897-908.

44. Wei B, Shin S, LaPorte D, Wolfe A, Romeo T. Global regulatory mutations in csrA and rpoS cause severe central carbon stress in Escherichia coli in the presence of acetate. J Bacteriol. 2000;182:1632-40.

45. Yan Z, Ezeji TC. Transcriptional analysis of Clostridium beijerinckii NCIMB 8052 to elucidate role of furfural stress during acetone butanol ethanol fermentation. Biotechnol Biofuels. 2013;6:66.

46. Coulter ED, Emerson JP, Kurtz DM Jr, Cabelli DE. Superoxide reactivity of rubredoxin oxidoreductase (desulfoferrodoxin) from Desulfovibrio vulgaris: a pulse radiolysis study. J Am Chem Soc. 2000;122:11555-6.

47. Zanello P. The competition between chemistry and biology in assembling iron-sulfur derivatives. Molecular structures and electrochemistry. Part I. $\left\{\mathrm{Fe}\left(\mathrm{S}_{\mathrm{YCyS}}\right)_{4}\right\}$ proteins. Coord Chem Rev. 2013;257:1777-805.

48. Alsaker KV, Paredes C, Papoutsakis ET. Metabolite stress and tolerance in the production of biofuels and chemicals: gene-expression-based systems analysis of butanol, butyrate, and acetate stresses in the anaerobe Clostridium acetobutylicum. Biotechnol Bioeng. 2010;105:1131-47.

49. van Bokhorst-van de Veen $H$, Abee T, Tempelaars M, Bron PA, Kleerebezem M, Marco ML. Short- and long-term adaptation to ethanol stress and its cross-protective consequences in Lactobacillus plantarum. Appl Environ Microbiol. 2011;77:5247-56.

50. Broadbent JR, Larsen RL, Deibel V, Steele JL. Physiological and transcriptional response of Lactobacillus casei ATCC 334 to acid stress. J Bacteriol. 2010;192:2445-58.

51. Wang Q, Venkataramanan KP, Huang H, Papoutsakis ET, Wu CH. Transcription factors and genetic circuits orchestrating the complex, multilayered response of Clostridium acetobutylicum to butanol and butyrate stress. BMC Syst Biol. 2013;7:120.

52. Horinouchi T, Tamaoka K, Furusawa C, Ono N, Suzuki S, Hirasawa T, et al. Transcriptome analysis of parallel-evolved Escherichia coli strains under ethanol stress. BMC Genom. 2010;11:579.

53. Lyu K, Meng Q, Zhu X, Dai D, Zhang L, Huang Y, et al. Changes in iTRAQbased proteomic profiling of the cladoceran Daphnia magna exposed to microcystin-producing and microcystin-free Microcystis aeruginosa. Environ Sci Technol. 2016;50:4798-807.

54. Maier T, Güell M, Serrano L. Correlation of mRNA and protein in complex biological samples. FEBS Lett. 2009;583:3966-73.

55. Zhao X, Xing D, Liu B, Lu L, Zhao J, Ren N. The effects of metal ions and L-cysteine on hydA gene expression and hydrogen production by Clostridium beijerinckii RZF-1 108. Int J Hydrogen Energy. 2012;37:13711-7.

56. Wang H, Qu Y, Li D, Zhou X, Feng Y. Evaluation of an integrated continuous stirred microbial electrochemical reactor: wastewater treatment, energy recovery and microbial community. Bioresour Technol. 2015;195:89-95.

57. Hurkman WJ, Tanaka CK. Solubilization of plant membrane proteins for analysis by two-dimensional gel electrophoresis. Plant Physiol. 1986;81:802-6.

58. Liu R, Wang Y, Qin G, Tian S. iTRAQ-based quantitative proteomic analysis reveals the role of the tonoplast in fruit senescence. J Proteomics. 2016;146:80-9.

59. Xie C, Mao X, Huang J, Ding Y, Wu J, Dong S, et al. KOBAS 2.0: a web server for annotation and identification of enriched pathways and diseases. Nucleic Acids Res. 2011;39:W316-22.

\section{Publisher's Note}

Springer Nature remains neutral with regard to jurisdictional claims in published maps and institutional affiliations. 